\title{
Ägyptisch-amerikanische Sozio-Histologie
}

\section{Erhard Taverna}

을

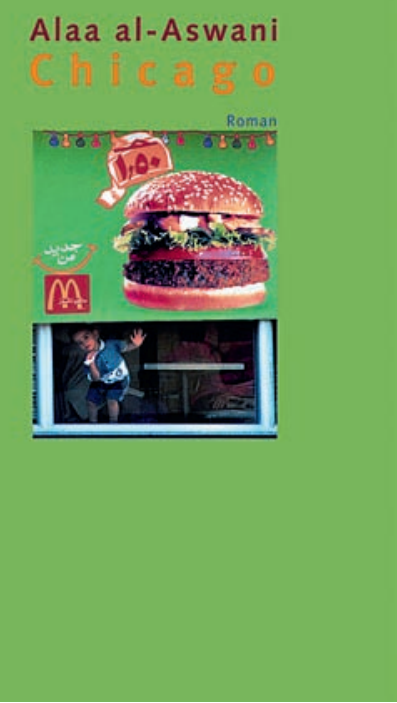

Der Roman «Chicago» des erfolgreichen ägyptischen Autors Alaa al-Aswani spielt in der medizinischen Fakultät einer der ältesten Universitäten der Vereinigten Staaten. Der in Kairo praktizierende Arzt und Schriftsteller kennt Chicago aus eigener Erfahrung von seinen Lehrjahren als Student der zahnärztlichen Medizin. Im Zentrum steht das Institut für Histologie, dessen Bewohner er mit folgenden Worten charakterisiert: «Die Histologen sind eine unbekannte Truppe, die für Wissenschaft Geld und Ruhm opfert und dabei im Lauf der Zeit die Eigenschaften von Handwerkern - Schreinern, Steinmetzen, Strohflechtern annimmt: Sitzfleisch, breiter Hintern, Wortkargheit, Beobachtungsgabe, scharfer, prüfender Blick, Geduld, Ruhe, klares Denken und hohe Konzentrationsfähigkeit.» Mitspieler sind in erster Linie Studenten mit einem Stipendium der ägyptischen Regierung: Shaimaa, ein fleissiges und frommes Landei vom Nil, das hier einen Kulturschock erlebt; Tarek, ein streng arbeitender Karrierist und unfreiwilliger Schwängerer; Danaa, ein betrügerischer Wendehals, der für den Geheimdienst Mokhabarat seine Landsleute bespitzelt, samt grausamem und korruptem Polizeivorgesetztem; sowie Samad, ein politischer Rebell, der als Opfer der gut etablierten geheimdienstlichen Zusammenarbeit von USA und General Mubarak endet. Das universitäre Milieu der Sti- pendiaten in Illinois stellt das Gewebe der ägyptischen Gesellschaft dar, auf das der Autor sein Mikroskop richtet, die USA liefert gleichsam den Objektträger dazu. Im Lehrkörper arbeiten auch zwei einheimische Professoren, Prof. Salah, mit einer Amerikanerin verheiratet, der auch nach dreissig Jahren keine neue Heimat gefunden hat, und Prof. Raafat, ein äusserlich überangepasster Immigrant, der seine Tochter an die Drogenszene verliert. Die erwähnten Figuren werden in Parallelerzählungen vorgestellt, die am Ende beim Auftritt des ägyptischen Diktators zusammenlaufen, der auf einer USA-Reise «seine» Studenten in Chicago besucht. Obwohl auch die amerikanische Seite mehrfach vertreten ist, unter anderen mit Carol, einer Jüdin, und John Graham, einem Professor und Alt-Hippie, der mit einer Schwarzen zusammenlebt, wirkt das Gastland klischeehaft, blass und konturlos. Die schlimmsten Vorurteile scheinen sich zu bestätigen: Wer dorthin auswandert, findet keine Wurzeln und scheitert, ständig bedroht von Dekadenz und moralischer Leere. Trotzdem ist der Roman lesenswert, weil dem Autor immer wieder überraschende Wendungen, gut beobachtete Szenen und präzise Personenporträts gelingen. Arabische und europäische Leserinnen und Leser werden mit kritischen Einsichten konfrontiert, beginnend mit der Worterklärung Chicago aus der Algonkin-Sprache, dem einzigen Relikt aus dem Vernichtungskrieg der christlichen Siedler gegen die Ureinwohner, bis zum Auftritt des Präsidentengenerals und seiner Hofclique, der mit Hilfe seiner westlichen Verbündeten das eigene Volk brutal unterdrückt.

Zum internationalen Literaturstar wurde der 1957 geborene Alaa al-Aswani mit seinem Erstling «Der Jakubijân-Bau». Obwohl das Buch gegen viele Tabuthemen wie Polizeigewalt, Korruption, Armut und sexuelle Ausbeutung verstösst, ist es nicht nur im Ausland, sondern auch in arabischen Ländern zu einem Bestseller geworden. Der Film zum Buch, an zahlreichen Festivals in Europa gezeigt, fand auch in Ägypten trotz Gerichtsprozessen und heftiger parlamentarischer Kritik ein zahlreiches Publikum. Der erste Roman von Alaa al-Aswani wirkt authentischer und farbiger als der zweite. Erzählt wird darin schonungslos offen von den Einwohnern eines Hauses in einem Wohnviertel Kairos, von den Armen in den glutheissen Wohncontainern 


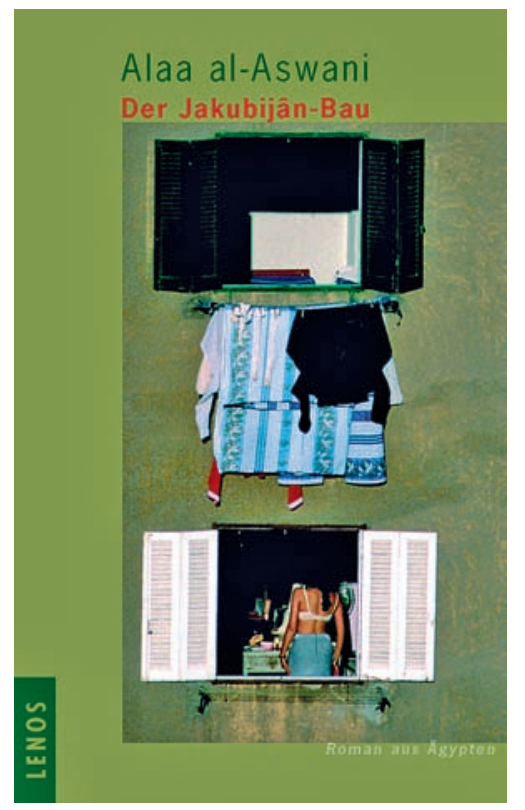

auf dem Hausdach, den Günstlingen des Regimes, den legalen Kanzleien und illegalen Handwerksbetrieben. Dieses tägliche Leben der Tagelöhner und ihrer Familien in der Hauptstadt ist geprägt von einer alle Gesellschaftsschichten, Kommerz, Politik und Religion durchdringenden Korrup- tion und Gewalt. Das Wohnhaus spiegelt die moderne Gesellschaft und ist gleichzeitig ein Geschichtsbuch Ägyptens der zweiten Hälfte des 20. Jahrhunderts.

Wer die Nachbarn am Mittelmeer verstehen will, findet in diesen Werken eine unverzichtbare Hilfe. Dass der Autor, buchstäblich aus der Praxis heraus, Zustände im eigenen Land anprangern kann, ohne dies mit dem Exil oder noch Schlimmerem zu büssen, gibt Anlass zu Hoffnung.

\section{Literatur}

- Alaa al-Aswani. Chicago. Basel: Lenos; 2008. 465 Seiten.

- Alaa al-Aswani. Der Jakubijân-Bau. Basel: Lenos; 2007. 372 Seiten.

\section{Versions françaises}

- Alaa el Aswany. Chicago. Arles: Actes Sud; 2007. 464 pages.

- Alaa el Aswany. L'Immeuble Yacoubian. Arles: Actes Sud; 2006. 336 pages.

\section{Versioni italiane}

- 'Ala Al-Aswani. Chicago. Milano: Feltrinelli; 2008. 310 pagine.

- 'Ala Al-Aswani. Palazzo Yacoubian. Milano: Feltrinelli; 2006. 216 pagine. 